\section{Case Reports in Ophthalmology}

\title{
Persistent Hypotony Associated with Immunosuppressive Therapy in Glaucoma Drainage Implant Surgery
}

\author{
Susana Duch Elena Milla Oana Stirbu David Andreu \\ ICO - Instituto Condal de Oftalmología, Barcelona, Spain
}

\section{Keywords}

Glaucoma drainage devices - Molteno implant - Ahmed valve - Immunosuppressant . Hypotony · Tubes · Mycophenolate mofetil · Corticosteroids · Cyclosporin

\begin{abstract}
Purpose: To describe the histopathology of non-valved implant capsules in three cases of persistent postoperative hypotony after the restrictive tube ligature was released in patients receiving immunosuppressive therapy. Observations: The macroscopic appearance of the capsules 3 and 4 months postoperatively was immature and loose. Microscopic examination disclosed extremely irregular thin tissue, with thicknesses ranging from 0.02 to $0.6 \mathrm{~mm}$, depending on the capsular location studied. Withdrawal of immunosuppressive therapy did not facilitate rebuilding of new capsules. Replacement with a valved implant device was necessary in two cases; the third case recovered with tapering of prednisone. Conclusions and Importance: The use of chronic systemic immunosuppressive therapy might interfere with capsular formation around the plates of drainage devices inducing persistent hypotony. In these cases, the use of valved implants might be safer.

(C) 2016 The Author(s)

Published by S. Karger AG, Basel
\end{abstract}

\section{Introduction}

The success of glaucoma drainage devices depends on the characteristics of the fibrous capsule that forms around the end plate that starts growing just after placement in the sub- 
conjunctival space [1]. While thin capsules predict lower postoperative intraocular pressure (IOP) levels, a lower IOP is not always better and chronic hypotony (IOP $<5 \mathrm{~mm} \mathrm{Hg}$ ) should be avoided. We present three cases with prolonged postoperative hypotony and the relation with immunosuppressive therapy.

\section{Findings}

\section{Case Report 1}

A 44-year-old Caucasian woman with juvenile rheumatoid arthritis treated with methylprednisolone $10 \mathrm{mg} / 24 \mathrm{~h}$ for 20 years was referred because of chronic refractory glaucoma in her right eye (RE) (visual acuity, 20/25). The IOP was $24 \mathrm{~mm} \mathrm{Hg}$ with high fluctuations despite timolol/dorzolamide and brimonidine twice daily. The corneal thickness was $490 \mu \mathrm{m}$. The cup/disc ratio was 0.9 with a severely affected visual field. In February 2008, a non-valved implant (Triple Acri.Tec, Acri.Tec GmbH, Berlin, Germany) (fig. 1) with a $6 / 0$ polyglactin ligature was placed over the two superior quadrants. Postoperative treatment with topical dexamethasone $(1 \mathrm{mg} / \mathrm{ml})$-tobramycin $(3 \mathrm{mg} / \mathrm{ml})$ and ciprofloxacin $(3 \mathrm{mg} / \mathrm{ml}$ ) was started along with her long-term preoperative systemic methylprednisolone. The IOP values decreased below $5 \mathrm{~mm} \mathrm{Hg}$ with the spontaneous release of the ligature 1 month later, and a spontaneous leakage through the conjunctival surgical suture was noticed (fig. 2). The eye remained quiet with no signs of inflammation; surgical closing of the leakage was necessary. The IOP remained below $5 \mathrm{~mm} \mathrm{Hg}$ for 4 months with no leak; therefore, we explanted one of the two plates. The IOP remained low during the following month, so oral methylprednisolone was withdrawn and the non-valved implant was replaced with a FP7 Ahmed valve (New World Medical Inc., Rancho Cucamonga, Calif., USA). After replacement, the IOP remained stable at 10-12 mm Hg. Histologic examination of the capsule showed irregular loose tissue with thicknesses ranging from 0.02 to $0.12 \mathrm{~mm}$ depending on the area studied (fig. 3).

\section{Case Report 2}

A 22-year-old Caucasian man with traumatic aphakia, aniridia, and immune-rejected penetrating keratoplasty (PK) in his RE was referred because of uncontrolled advanced glaucoma. The left eye (LE) was normal. The IOP in his RE was $62 \mathrm{~mm} \mathrm{Hg}$ on maximal tolerated hypotensive medications. He had been taking oral prednisolone for 1 year. One day later, a double-plate Molteno implant (Molteno Ophthalmic Ltd., Dunedin, New Zealand) with a 6/0 polyglactin ligature and anterior vitrectomy were performed. Postoperative treatment with topical dexamethasone $(1 \mathrm{mg} / \mathrm{ml})$-tobramycin $(3 \mathrm{mg} / \mathrm{ml})$ and ciprofloxacin $(3 \mathrm{mg} / \mathrm{ml}$ ) was started along with his previous oral prednisolone. Ten days later, another PK and a complete pars plana vitrectomy were performed, and a sulcus fixation intraocular lens was implanted for aniridia. Systemic immunosuppression, i.e., $150 \mathrm{mg}$ of cyclosporine and $1 \mathrm{~g}$ of mycophenolate mofetil, was added to the treatment. On day 24 after shunt implantation, spontaneous release of the absorbable ligature provoked severe hypotony, with leaking dehiscence that was repaired. Because the hypotony lasted for 2 months, we tapered the immunosuppressive treatment with no response. The IOP remained below $5 \mathrm{~mm} \mathrm{Hg}$, so the double Molteno implant was replaced with a FP7 Ahmed valve. Macroscopically, the capsular tissue was thin and irregular (fig. 4). The pathology examination showed irregular areas of loose collagen tissue with thicknesses of $0.02,0.18$, and $0.6 \mathrm{~mm}$. The IOP recovered to the 
low teens and another PK with administration of systemic immunosuppressant was performed 6 months later.

\section{Case Report 3}

A 15-year-old Iranian girl diagnosed with bilateral glaucoma secondary to the AxenfeldRieger syndrome was referred in January 2012 because of uncontrolled IOP in the LE. The glaucoma was medically controlled in the RE. The LE visual acuity was counting fingers and the IOP was $44 \mathrm{~mm} \mathrm{Hg}$ with maximal tolerated topical treatments and acetazolamide 250 $\mathrm{mg} / 8 \mathrm{~h}$. Slit-lamp examination of the LE showed an edematous cornea that prevented further examination. The lens and iris diaphragm were attached to the cornea. A previously implanted Ahmed capsule bulged through the superonasal conjunctiva. On January 30, a pars plana vitrectomy with lensectomy through an Eckhard prostheses and a PK along with a first-stage Baerveldt-350 implant (Abbott Medical Optics, Abbott Park, Ill., USA) were performed. Immunosuppressive therapy was started with oral prednisone $60 \mathrm{mg} / 24 \mathrm{~h}$ and cyclosporine $10 \mathrm{mg} / 12 \mathrm{~h}$ along with topical dexamethasone $(1 \mathrm{mg} / \mathrm{ml})$-tobramycin $(3 \mathrm{mg} / \mathrm{ml})$ and ciprofloxacin $(3 \mathrm{mg} / \mathrm{ml})$. After returning to Iran, the patient came back 48 days later without tapering the systemic steroids as instructed. The eye was quiet and the new cornea allowed good fundus and anterior segment visualization; the second stage of drainage implant surgery was performed and the intraocular portion of the tube was placed in the superonasal quadrant in the posterior chamber. During surgery, we visualized the aqueous humor flowing freely from the implant plate due to the absence of the capsule. A 6/0 polyglactin ligature around the tube was placed to avoid postoperative hypotony. The cyclosporine and oral prednisone were tapered.

\section{Discussion and Importance}

The capsular thickness and permeability around drainage devices determine the rate of aqueous outflow. During the early postoperative period, the inflammatory and fibrovascular response in the growing capsule determines its histologic structure. Systemic corticosteroids have been previously reported to cause thinning of implant capsule [2], and the use of oral prednisone along with flufenamic acid due to their anti-inflammatory effect in the capsule [3] has been advised for preoperative and postoperative therapy to decrease the final wall thickness, thus increasing its permeability [4]. Additional prospective studies have not demonstrated the benefits of adjuvant anti-inflammatory and antimitotic treatments, although some indirect observations have shown some inhibitory effect on the capsular formation [5]. In 2003, Molteno et al. [6] reported the histologic characteristics of the early fibroproliferative response and the later fibrodegenerative response in capsules that formed around Molteno implants. The authors observed thinner capsules in patients receiving longterm systemic prednisone, diclofenac, and colchicine. Ceballos et al. [7] and Da Mata et al. [8] reported persistent hypotony in four uveitic eyes after Baerveldt-350 and Ahmed valve surgery. No clear etiopathogenesis of this complication was described. The current patients had been receiving long-term oral immunosuppressive treatment during the early postoperative period, when the capsules were forming. In case 1, the patient had been taking oral methylprednisolone for 20 years, and in case 2, the anti-inflammatory effect of oral prednisolone for 1 year was increased as a result of the newly introduced immunosuppressive drugs. In case 3 , the patient had taken an overdose of prednisolone along with the immunosuppressive therapy for more than 1 month. In all cases, the resulting capsules were macro- 
scopically irregular and thin, leading to leaking and hyperfiltration. The current results indicate that glaucoma surgeons should be aware of systemic treatments that might alter the scarring process when planning a tube surgery. It seems reasonable to suggest that in these cases, valved implants might better maintain IOP levels within normal ranges, thus avoiding dangerous chronic postoperative hypotony.

\section{Statement of Ethics}

The authors have no ethical conflicts to disclose.

\section{Disclosure Statement}

The authors have no conflicts of interest to disclose.

\section{References}

1 Minckler DS: Experimental studies of aqueous filtration using the Molteno implant. Trans Am Ophthalmol Soc 1987; 135:368-392.

2 Molteno ACB: New implant for drainage in glaucoma. Clinical trial. Br J Ophthalmol 1969;53:606-615.

- Molteno AC, Straughan JL, Ancker E: Control of bleb fibrosis after glaucoma surgery by antiinflammatory agents. S Afr Med J 1976;50:881-885.

4 Molteno AC, Ancker E, Van Biljon G: Surgical technique for advanced juvenile glaucoma. Arch Ophthalmol 1984;102:51-57.

5 Alvarado J, Hollander DA, Juster RP, Lee LC: Ahmed valve implantation with adjunctive mitomycin C and 5-fluorouracil: long-term outcomes. Am J Ophthalmol 2008;146:276-284.

-6 Molteno AC, Fucik M, Dempster AG, Bevin TH: Otago Glaucoma Surgery Outcome Study: factors controlling capsule fibrosis around Molteno implants with histopathological correlation. Ophthalmology 2003;110:2198-2206.

7 Ceballos EM, Parish RK 2nd, Schiffman JC: Outcome of Baerveldt glaucoma drainage for the treatment of uveitic glaucoma. Ophthalmology 2002;109:2256-2260.

8 Da Mata A, Burk SE, Netland PA, et al. Management of uveitic glaucoma with Ahmed glaucoma valve implantation. Ophthalmology 1999;106:2168-2172. 


\section{Case Reports in Ophthalmology}
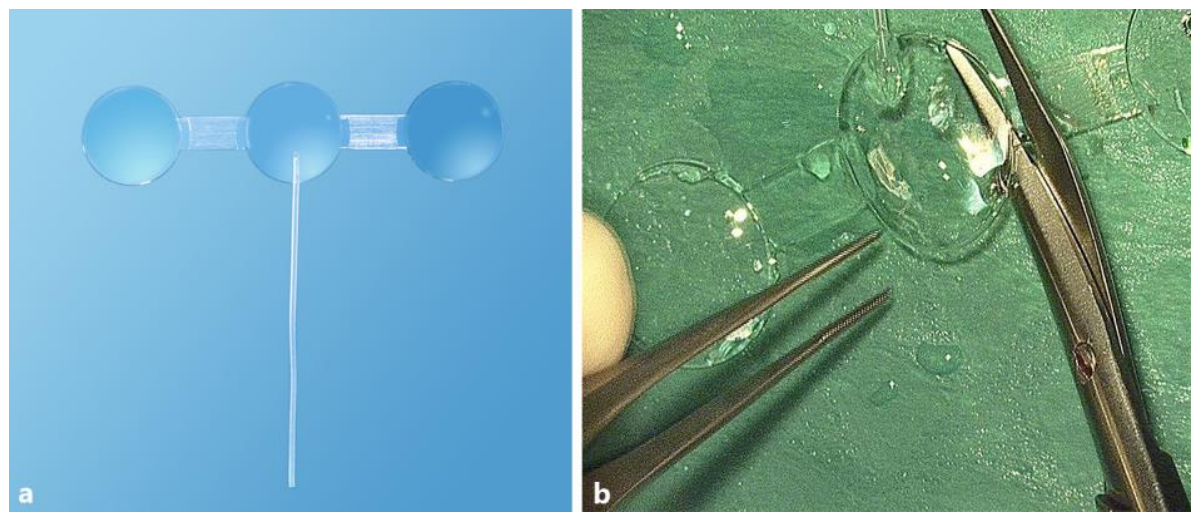

Fig. 1. a The Triple Acri.Tec implant is a triple plate implant made of hydrophobic polydimethylsiloxane. The silicon disc measures $11.7 \mathrm{~mm}$ in diameter with $0.3 \mathrm{~mm}$ of total thickness. The silicon tube is attached to the central plate, and has a lumen of $0.25 \mathrm{~mm}$ and an outer diameter of $0.64 \mathrm{~mm}$. It can be customized to one, two or three plates. $\mathbf{b}$ In case 1, the implant was customized for two plates.

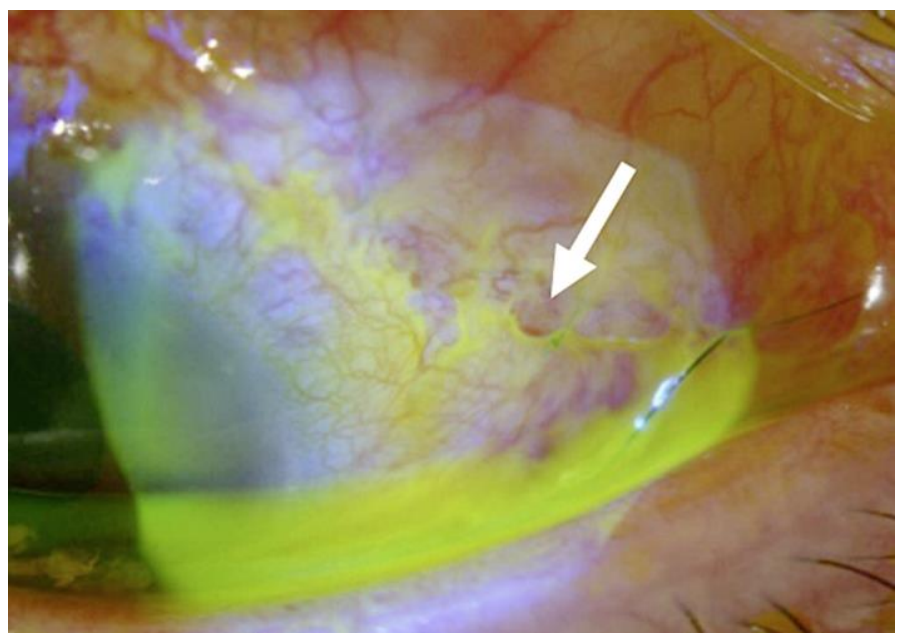

Fig. 2. Case 1. Just after the spontaneous release of the ligature, aqueous leakage was noticed over the conjunctival suture below the second superotemporal plate of the Acri.Tech implant (arrow). 


\section{Case Reports in Ophthalmology}

\begin{tabular}{l|l}
\hline Case Rep Ophthalmol 2016:7:132-137 \\
\hline DOI: 10.1159/000447528 & $\begin{array}{l}\text { C } 2016 \text { The Author(s). Published by S. Karger AG, Basel } \\
\text { www.karger.com/cop }\end{array}$ \\
\hline
\end{tabular}

Duch et al.: Persistent Hypotony Associated with Immunosuppressive Therapy in Glaucoma Drainage Implant Surgery

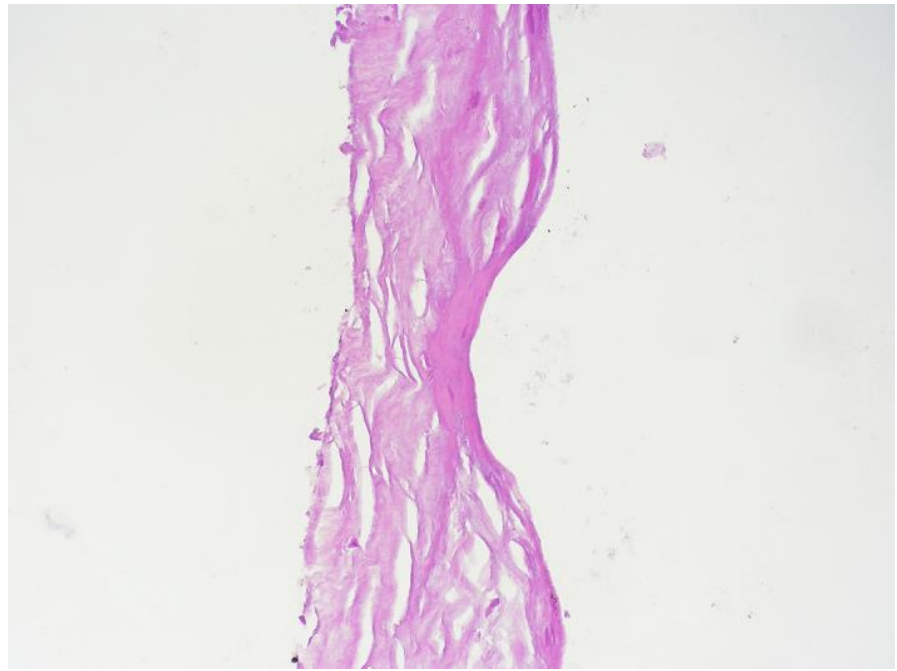

Fig. 3. Case 1 (hematoxylin and eosin, $\times 20$ ). The capsule at 5 months postoperatively. The inner wall is comprised of hyalinized fibrosis $(0.02 \mathrm{~mm})$ and outer layer of edematous collagen tissue $(0.04 \mathrm{~mm})$.

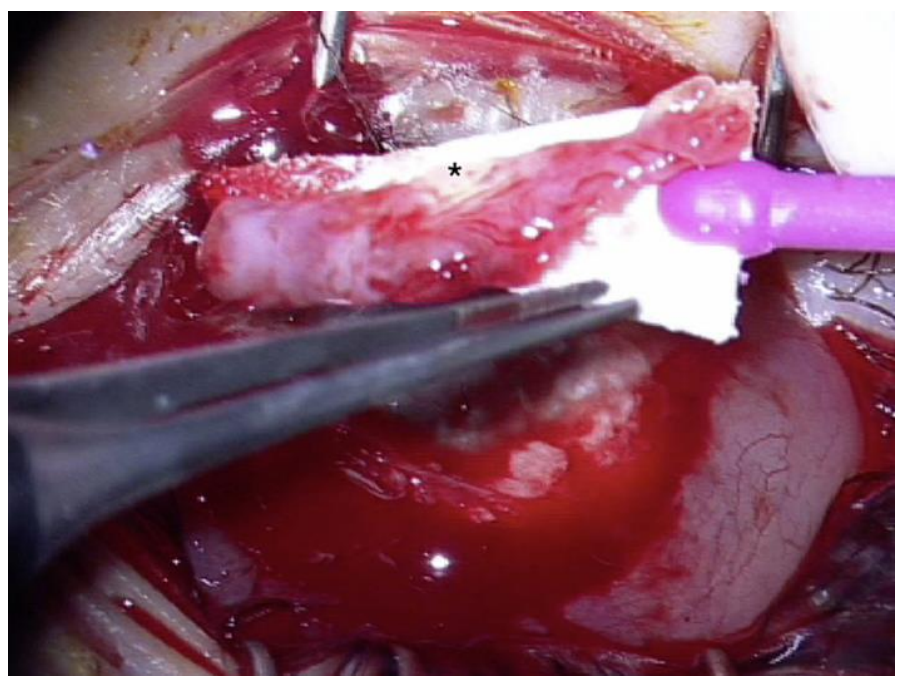

Fig. 4. Case 2. A macroscopic specimen shows the surgically excised capsule, which is irregular with extremely thin areas $\left(^{*}\right)$. 